Short report

\title{
The development of conceptual interests in young children
}

\author{
Joyce M. Alexander ${ }^{a, *}$, Kathy E. Johnson ${ }^{b}$, \\ Mary E. Leibham ${ }^{\mathrm{c}}$, Ken Kelley ${ }^{\mathrm{a}}$ \\ a Indiana University, Bloomington, IN 47405-1006, United States \\ ${ }^{\mathrm{b}}$ Indiana University-Purdue University Indianapolis, IN, United States \\ c University of Wisconsin-Eau Claire, Eau Claire, WI, United States
}

\begin{abstract}
We conducted a longitudinal analysis of the relative intensity and duration of interests associated with conceptual domains between the ages of 4 and 6 years, respectively. Results indicated a significant portion of preschool children do sustain an interest in conceptual domains during some portion of their childhood. Expected gender differences were found, with boys more likely to express an interest in a conceptual domain than girls. A latent growth curve analysis revealed that the probability of exhibiting a conceptual interest declined as school began, though the rate of that decline was similar for both boys and girls. Potential explanations for the decrease in conceptual interests as school begins are considered.
\end{abstract}

(C) 2007 Elsevier Inc. All rights reserved.

Keywords: Conceptual development; Cognitive development; Interests; Gender differences

Over two decades ago, Chi and her collaborators initiated a program of research focused on children who were intensely interested in the conceptual domain of dinosaurs (Chi, Hutchinson, \& Robin, 1989; Chi \& Koeske, 1983; Gobbo \& Chi, 1986). This work prompted a close consideration of whether children's domain-specific knowledge acquisition could account for changes that previously had been attributed to age-related developmental processes (Johnson \& Eilers, 1998). Sustaining interests on conceptual domains can lead to a number of benefits for learning-increased knowledge and persistence (Hidi, 2000; Renninger, 1992), heightened attention (Renninger \& Wozniak, 1985), and deeper levels of processing (Schiefele \& Krapp,

\footnotetext{
* Corresponding author at: Department of Counseling and Educational Psychology, Indiana University, 201 N. Rose, Room 4038, Bloomington, IN 47405-1006, United States. Tel.: +1 812856 8352; fax: +1 8128568333.

E-mail address: joalexan@indiana.edu (J.M. Alexander).
} 
1996). Recent research has begun to consider supports for the initial acquisition of conceptual interests (Johnson, Alexander, Spencer, Leibham, \& Neitzel, 2004; Leibham, Alexander, Johnson, Neitzel, \& Reis-Henrie, 2005). The aim of the present study, however, was to conduct a long-term developmental analysis of the degree to which conceptual interests are sustained by boys and girls between ages 4 and 6 years-a period that spans the transition to school.

Interests refer to relations between individuals and objects, domains, events, or topics that are personally meaningful (Fink, 1994). Interest is both a psychological state and an individual predisposition, though the present investigation focuses on the latter. When an interest is relatively enduring it is termed an individual interest (Renninger, 1989, 2000). In contrast, situational interests (which could eventually become individual interests) are more fleeting and are triggered by salient stimuli (Hidi \& Renninger, 2006). Although some researchers have suggested that individual interests are not well-established until preadolescence (Krapp, 2002), Renninger (1990, Renninger \& Wozniak, 1985) adopts a more lenient criterion and suggests that such interests may emerge in early childhood. This view fits well with retrospective reports of adult experts who indicate that their interests emerged early in life (Ericsson \& Crutcher, 1990), and with parents' reports that roughly $30 \%$ of early preschool age children exhibit noticeably intense interests (DeLoache et al., in press).

One of the chief consequences of conceptual interests appears to be the development of fairly rich, oftentimes taxonomically organized knowledge aligned with domains that are relatively narrow in scope. Researchers interested in the impact of expertise on children's and adults' categorization and concept use have analyzed how such domains support mastery of subordinate level concepts through perceptual learning and the acquisition of semantic knowledge on topics such as dinosaurs (Alexander, Johnson, \& Schreiber, 2002; Alexander et al., 2008; Chi \& Koeske, 1983; Gobbo \& Chi, 1986; Johnson \& Eilers, 1998; Johnson, Scott, \& Mervis, 2004), birds (Johnson \& Mervis, 1994, 1997, 1998; Mervis, Pani, \& Pani, 2003), and even artificial domains such as Pokemón (Lavin, Gelman, \& Galotti, 2001).

Conceptual domains typically have not been considered in either analyses of talent development or children's preferred play objects. Parent reports confirm, however, that interest in such domains motivates some children to pursue domain-relevant information through books (typically read to them by others), digital media, videotapes, and toy models that support learning (Johnson, Alexander, et al., 2004). As a consequence, conceptual interests tend to promote "fact collecting" rather than the development of new skills or play behaviors. Children who manifest conceptual interests during early childhood tend to be highly verbal and are typically boys (Alexander et al., 2002; Johnson, Alexander, et al., 2004; Johnson \& Eilers, 1998; Johnson, Scott, et al., 2004).

Interest in conceptual domains has the potential to enhance learning both prior to and following the transition to school. Topic interest is highly correlated with deep-level indicators of understanding, such as elaborations and correct responses to comprehension questions (Schiefele \& Krapp, 1996). Schiefele (1998) reports correlations averaging .30 between interest and global indicators of learning (including both grades and indices of achievement), with interest typically explaining about $10 \%$ of the variance in learning outcomes. One way children with conceptual interests may construct such deep understandings is through question-asking (Chouinard, 2007; Renninger, 1992). Question-asking in biologically relevant domains could potentially support a better understanding of evolution, taxonomic relations, and causal connections between physical and behavioral traits (Watson, 2001). It seems possible that an additional consequence of early interests is that they become related to children's self-concepts and affect subsequent 
attention toward domain-relevant information in later childhood (Renninger, 1992), which could ultimately influence the selection of extracurricular activities and possibly even vocational training in adolescence and early adulthood.

Previous research on interests has established differences in the proportions of girls and boys manifesting conceptual interests - particularly those aligned with science domains (FollingAlbers \& Hartinger, 1998; Johnson, Alexander, et al., 2004; Leibham et al., 2005). Several theories have been proposed to explain such differences. Gender differences may be fueled by boys' tendency to systematize, which refers to the drive to construct and to analyze systems of phenomena that are lawful, finite, and deterministic (Baron-Cohen, 2002, 2003). Of course, parents' reports of their child's interests also may be influenced by their views about appropriate gender-typed play objects (Ford, Brickhouse, Lottero-Perdue, \& Kilttleson, 2006; Lytton \& Romney, 1991; Martin, 1999). Finally, boys' gravitation toward conceptual interest objects such as dinosaur models, telescopes, and bug collecting kits, may be driven by such objects' promotion as male-typed items in the commercial marketplace. Girls' may consider such objects to be less desirable as the result of such marketing and may spend considerably less time in early childhood interacting with them (Moller \& Serbin, 1996).

We hypothesize that a significant obstacle to the maintenance of preschool interests over long periods of time is the transition to formal schooling. After the preschool years end, the child's home life becomes enmeshed with the cultures of school and neighborhood and new play and recreation possibilities abound (Johnson, Christie, \& Yawkey, 1999). Teachers' report having little leeway to build children's specific interests into early elementary curricula (Fernie, 1988; Klugman, 1990). In addition, children are exposed to an increased array of potential situational interest triggers in school and have less free time to devote to their own individual interests outside of school (Krapp \& Fink, 1992). Very little is known about the impact of schooling on the maintenance of early conceptual interests. The present study will explore this issue for a relatively large cohort of children.

\section{Method}

\subsection{Participants}

Participants included 215 children (90 girls, 125 boys) recruited between the ages of 4.0 and 4.6 $(M=4.2)$. We interviewed participants at a baseline testing session during which children and their parents visited a laboratory either on an urban university campus (77\% of the sample) or in a rural university town. We subsequently contacted parents by phone or e-mail every 2 months for 24 months. A total of 204 child-parent pairs completed at least 10 of the 13 contacts and were retained for the analyses presented in Part I of the results (120 males). All 215 children are included in the analyses in Part II. Most of the sample was Caucasian (86\%), with 5\% African American, 3\% Hispanic/Latino, and very small percentages of Asian, Native American, and biracial children. The median income bracket of the participating families was $\$ 55,000-\$ 65,000$, and the majority of parents had completed a baccalaureate degree. The numeric median of the household income range was assigned as a proxy and a standard deviation was computed for the group (S.D. $=\$ 35,000)$. Families were recruited through brief articles in local newspapers, flyers posted in preschools and doctors' offices, and through Listservs. Parents were told that the study was focused on the types of play interests developed by preschoolers. Children received small gifts during annual laboratory visits as compensation. 


\subsection{Measures and procedures}

\subsubsection{Bimonthly parent report measure}

Over the 24 months of the study, each parent provided information about their child's play interests and related activities through 13 bimonthly interviews. Three interviews were administered in the laboratory through written questionnaires (administered as children completed a cognitive test battery), while the remaining 10 interviews were conducted either by telephone or email, depending on parents' preferences. Parents reported the amount of free play-time typically available (on weekdays and weekend days), and the child's preferred activities during free play. We also asked about the child's preferred television shows, video programs, and books, and the relative amounts of time spent engaged with these media. Later in the interview, we asked parents if their child's interests appeared very focused, with the child tending to keep the same interest for an extended period of time (i.e., 1 month) or if the child seemed to be interested in lots of different things, with his or her interests changing often (target questions were embedded among several other filler questions). If a child's interest was described as focused, parents were asked to identify the particular topic or domain of play (which was then coded as an individual interest).

Interview data were used to derive variables that characterized children's interest profiles. First, we recorded the proportion of contacts in which parents reported their child to have exhibited an individual interest (regardless of interest foci). Second, we recorded the total number of interest foci that were exhibited by the child across the 24 months. Closely related interests were collapsed (e.g., coloring and painting were counted as a single interest in "arts and crafts"), but otherwise we counted all interests mentioned by parents. Finally, we calculated the temporal duration (in months) of each individual interest that parents reported. This enabled us to characterize the mean length of time that particular interests were sustained, as well as the longest period of time for which a particular interest was maintained. We reasoned that both the proportion of parental reports in which a child was considered to exhibit a significant, focused interest and the temporal duration of individual interests could independently contribute to the child's interest profile (i.e., some children might consistently exhibit a single interest, while others may express an interest at all or most points of contact, but those interests may change relatively often and thus have comparably brief durations). We therefore examined three variables: (1) proportion of contacts (out of 13) for which focused interests were reported (range 0-1); (2) total number of interest topics (range 0-10); and (3) number of contacts across which the longest-term interest was maintained (range $0-13$ ).

\section{Results}

We first explore the relative prevalence and intensity of conceptual interests among the entire cohort. We also compare the prevalence of conceptual interests to other common interests. Second, we explore maintenance of conceptual interests using a latent growth curve model.

\subsection{Conceptual interest prevalence and intensity}

We first classified each interest the parent reported into one of 11 different interest areas derived from previous research on play and interest types (Renninger \& Wozniak, 1985; Saracho, 1995; Smilansky, 1968). Determination of interest area was based on parents' descriptions of how children typically engaged in the interest domain. For example, a child with an interest in enacting "pretend adventures" with small plastic dinosaurs and other animals would be classified 
Table 1

Descriptive information for parental reports of children's interest categories across 24 months

\begin{tabular}{|c|c|c|c|c|c|c|c|}
\hline \multirow[t]{3}{*}{ Interest category } & \multicolumn{7}{|c|}{ Proportion of contacts in which focused interest is reported } \\
\hline & \multirow[t]{2}{*}{ Examples } & \multirow[t]{2}{*}{ Min. } & \multirow[t]{2}{*}{ Max. } & \multicolumn{2}{|l|}{ Boys } & \multicolumn{2}{|l|}{ Girls } \\
\hline & & & & Mean & S.D. & Mean & S.D. \\
\hline Conceptual & Dinosaurs, airplanes, horses & .00 & 1.00 & .31 & .35 & .09 & $.22^{*}$ \\
\hline Sociodramatic & Pretend and adventure play & .00 & 1.00 & .16 & .20 & .28 & $.28^{* *}$ \\
\hline Creative arts & Crafts, Drawing & .00 & 1.00 & .03 & .07 & .20 & $.28^{* *}$ \\
\hline Constructive/building & Legos, blocks & .00 & 1.00 & .09 & .08 & .01 & $.02^{*}$ \\
\hline Sports/dance & Soccer, Ballet & .00 & 1.00 & .07 & .20 & .01 & $.03^{*}$ \\
\hline Games with rules & $\begin{array}{l}\text { Board and card or strategic-based } \\
\text { computer games }\end{array}$ & .00 & .85 & .06 & .12 & .03 & $.06^{*}$ \\
\hline Literacy arts & Reading, Writing & .00 & .50 & .03 & .07 & .06 & $.09^{* *}$ \\
\hline Skill & $\begin{array}{l}\text { Based on strategies and/or } \\
\text { practice such as chess, piano }\end{array}$ & .00 & .92 & .02 & .10 & .03 & .07 \\
\hline Outside/physical activity & Swinging, hiking, riding bicycles & .00 & .38 & .02 & .05 & .03 & .05 \\
\hline TV/radio & Television, radio & .00 & .20 & .01 & .03 & .01 & .04 \\
\hline Play with others & $\begin{array}{l}\text { Preference for partner (e.g., } \\
\text { mom), not activity }\end{array}$ & .00 & .23 & .01 & .02 & .01 & .01 \\
\hline
\end{tabular}

Note. We included only those children who had relatively complete reports of their interests over the 24 months in this analysis (at least 10 out of 13 contacts were complete, $n=204$ ).

${ }^{*} p<.05, t(203)$, boys higher than girls.

${ }^{* *} p<.05, t(203)$, girls higher than boys.

as having an interest in sociodramatic play. A similar child who also was reported to collect models of dinosaurs and to particularly enjoy reading about different kinds of dinosaurs would be classified as having a conceptual interest. Conceptual interest classifications generally were based on whether children routinely engaged in activities that promoted the acquisition of declarative knowledge. Initially, two authors simultaneously coded $20 \%$ of the data. Authors agreed in $95 \%$ of classifications, and disagreements were resolved through discussion. One author then coded the remaining data.

As can be seen in Table 1, children were reported to exhibit relatively high levels of interest in areas related to conceptual and sociodramatic interests across the 2-year period. The interest areas of creative arts and constructive/building also were relatively prevalent between 4 and 6 years of age, respectively. $t$-Tests comparing the proportion of parental reports in each domain of interest revealed expected gender differences (see Table 1). Parents of boys reported more frequent interests in conceptual, sports, games with rules, and constructive/building domains. Girls more often exhibited interests in sociodramatic, creative arts, and literacy domains. Children's interests also varied in longevity. Some parents rarely reported their child to exhibit focused interests $(6 \%$ of participants; <.10 of all contacts) while others indicated that their child always had a focused interest (21\% of participants). For seven of the interest domains at least one child maintained a specific interest across all 13 contacts. ${ }^{1}$ The most frequently mentioned interest for each child was

\footnotetext{
${ }^{1}$ Maximum duration scores were calculated for particular interests based on the specific interest topic, not the more general domain of interest. For example, if a child was reported to have two conceptual interests (bugs, horses), the maximum duration score for each was based only on reports of the specific interest topic (not conceptual interests, in general).
} 
maintained on average for 11 months (5.5 bimonthly contacts). Finally, children varied in terms of the number of different foci for which they demonstrated an interest across the 24 months. Although the average number of foci for which children expressed an interest was $4,7 \%$ of participants were reported to be interested in only a single topic, while $5 \%$ of participants were reported to exhibit an interest in eight or more topics throughout the 24-month period. These numbers are similar to those provided by Renninger and her colleagues (Renninger \& Wozniak, 1985) who reported an average of five play interests among nursery school children based on their observations of play object preferences.

There were no gender differences in the proportion of contacts for which children were reported to exhibit focused interests, as evidenced through $t$-tests; males .71, females $.65, t(203)=1.40$, S.E. $=.04$. Nor were there gender differences in either the duration of the most intense interest; males $=6.06$ contacts, females $=5.24$ contacts, $t(203)=1.58$, S.E. $=.52$; or the number of different foci across the 24 months, males $=4.09$, females $=4.12, t(203)=.10$, S.E. $=.29$. Thus, boys and girls have very similar patterns of interest expression, except for the specific activity domain or topic of interest.

There were 103 children reported to have an interest in a conceptual domain at some point between the age of 4 and 6 (69\% of boys and 26\% of girls). Eleven girls (14\%) and 34 boys (28\%) were reported to have a conceptual interest for only one or two contacts during the 24 months. However, 35 boys (29\%) and 5 girls (7\%) were reported to maintain their interest in conceptual domains for at least 1 year. Of those children who were reported to exhibit at least one conceptual interest, the percentage of those who went on to maintain that interest for at least 1 year was relatively similar across boys (40\%) and girls (23\%). Interestingly, the proportion of contacts in which a conceptual interest was reported by the entire group declined between years 1 and year 2 of the study, paired sample $t(203)=2.97, p<.01$, Mean $n_{\text {diff }}=.04$, S.E. $=.015$, Cohen's $d$ using original standard deviations = 14 (Dunlop, Cortina, Vaslow, \& Burke, 1996) or Cohen's $d=.42$ using paired $t$-test value (Rosenthal, 1991). This was the only interest domain to show a significant decline, all other $t(203)=n s$.

\subsection{Conceptual interest maintenance}

To longitudinally examine the decline in conceptual interests more closely, we used a latent growth curve model for dichotomous outcomes (here the dichotomous outcome was conceptual interest expressed vs. not expressed), which was modeled over the 13 contacts across 2 years. We modeled the logit, though report our findings as probabilities for ease of interpretation (probability $=\exp (\operatorname{logit}) /[1+\exp (\operatorname{logit})]$, where $\exp ()$ is the antilogarithm function; e.g., Hedeker \& Gibbons, 2006). The intercept represents the probability of having a conceptual interest at age 4 and the slope represents the change in probability across time ( 24 months). The use of the straight-line change model also enabled us to retain children for whom parents had not completed all of the bimonthly interviews, as complete data on the dependent variable for each participant is not required (when it is assumed data are missing at random; e.g., Singer \& Willett, 2003). Thus, in this section, data from all 215 children are included in the analyses.

A model was run to determine the likelihood that having a conceptual interest changed over time, with gender included as the predictor. Fig. 1 illustrates the model-implied probability that a child will develop a conceptual interest. Separate lines are shown for boys and girls since the analysis was conditional on gender. The starting points (intercepts) differ significantly for boys and girls indicating a higher likelihood of boys developing a conceptual interest than girls, Beta 


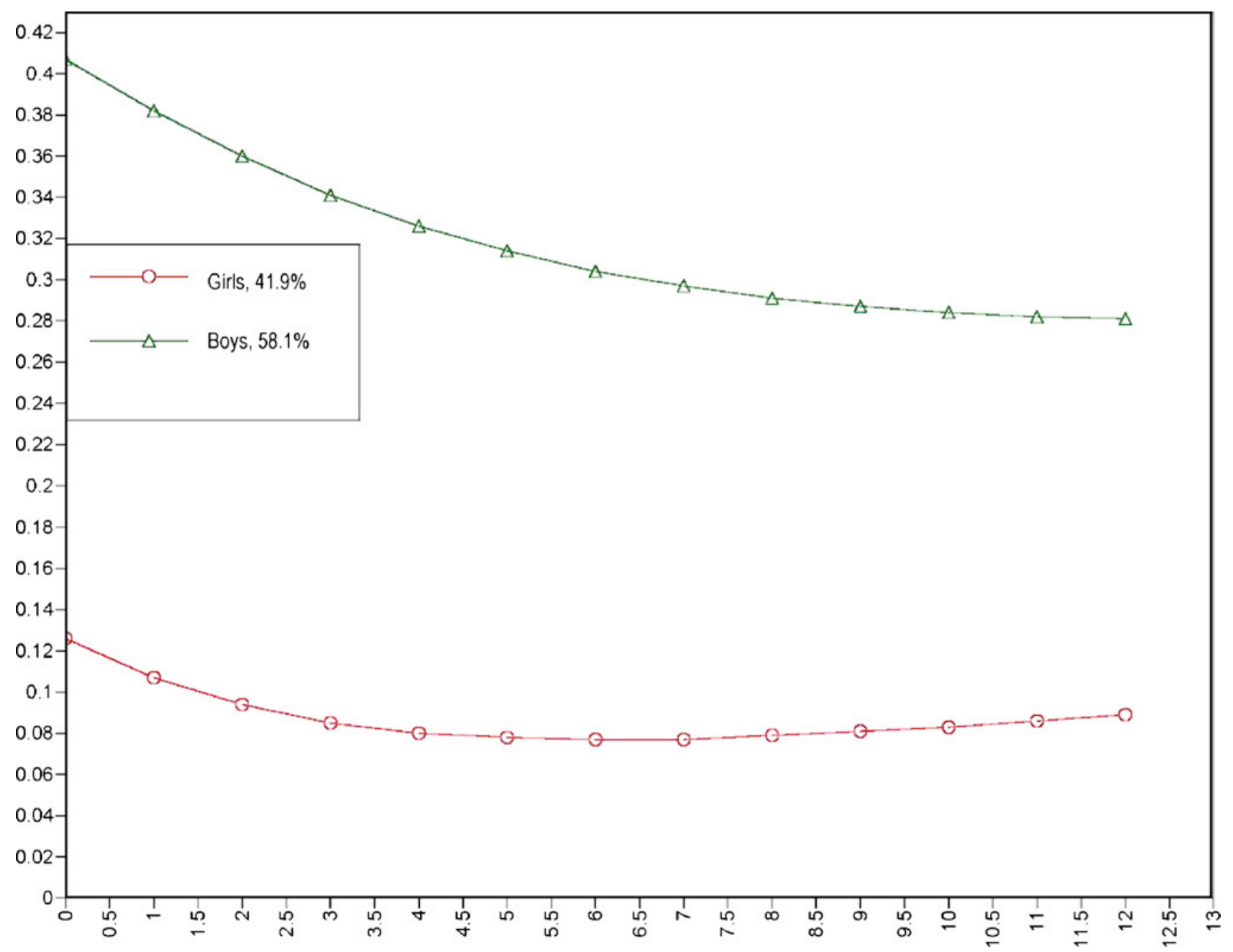

Fig. 1. Implied proportion of children with conceptual interests over 24 months.

estimate $=-3.46$, S.E. $=.73, z=4.77, p<.001$. The slopes (or change over time) for both boys and girls are significantly different from zero, Beta estimate for girls $=-.39$, S.E. $=.13, z=-3.01$, $p<.01$ and Beta estimate for boys $=-.25$, S.E. $=.07, z=-3.8, p<.001$, indicating a significant decline in the likelihood of conceptual interests for both genders over 24 months. As can be seen from the figure, however, the slopes for boys and girls are not significantly different from each other.

\section{Discussion}

The rich data derived from the present study provides the first longitudinal analysis of the prevalence, duration, and intensity of conceptual interests in children between ages 4 and 6 years. Although some researchers maintain that individual interests do not emerge until adolescence or adulthood (Krapp, 2002), many parents clearly characterized their child's conceptual interest as long-standing and prone to dominating the child's preferred activities-both of which are key indicators of individual interests. Conceptual interests were relatively prevalent throughout our sample. Approximately $50 \%$ of children were reported to have an interest in a conceptual domain at some point during the 2 years. Only a small percentage of children, however, developed a long-term interest in a conceptual domain (40 children, $20 \%$ of the sample).

A latent growth curve model confirmed earlier reports that boys were far more likely to develop a conceptual interest by the age of 4 than were girls (Johnson, Alexander, et al., 2004). The present 
analysis extended this work, showing that both boys and girls maintain conceptual interests over time at about the same rate. Most interestingly, the model clearly notes a significant decrease in the prevalence of conceptual interests following the transition to formal schooling. In contrast, interests focused on nonconceptual domains did not show a similar decline. We next turn to possible explanations for this finding.

Children with conceptual interests may find themselves in a dilemma as school begins. They may be highly interested in a domain and be accustomed to receiving individualized support for the interest from parents and preschool teachers. Conceptual interests are one of the few early childhood interests where a child tends to rely on parents or other older individuals to provide a significant amount of relevant information (Leibham et al., 2005). Middle class children almost certainly have opportunities to ask curiosity questions and to receive informative answers during the relatively unstructured preschool years to help feed their growing interest in a conceptual domain (Renninger, 1992; Chouinard, 2007). In contrast, the elementary school classroom involves more children, more stringent curricular objectives (particularly with an increased societal emphasis on assessment and accountability), and there may be relatively little time for children to ask questions pertinent to their interest and receive individualized answers. School environments may simply not accommodate the long-term pursuit of relatively narrow interests, particularly among young children that are still quite dependent on adults and older children for access to information (Prenzel, 1992).

Young children with conceptual interests may also experience new social pressures as they begin to form friendships in elementary school. Friends are an important source of social support and friendships often are based on common ground (Johnson et al., 1999). Other children in the child's class may not happen to know much about-or be very interested in frogs, horses, or dinosaurs. Thus children may intentionally suppress their interests and knowledge (when they do not align with those of their classmates) in order to nurture developing friendships.

As children get older, they may discover that learning is less playful and more apt to entail hard work (Hidi, 2000). We know that as children age, their interest in school-based subjects deteriorates (Eccles \& Midgley, 1990). By middle school, non-academic topics are listed as interest foci far more often than academically oriented topics (Ainley, Hidi, \& Berndorff, 2002). Some of this drift from academically oriented interests may be the result of a mismatch between the knowledgerich interests children bring to the classroom and the particular curricula and opportunities for learning that the school provides. Future research that compares the interest maintenance of children assigned to more structured classrooms with that of children who are homeschooled or enrolled in smaller, more child-centered classrooms would be most helpful in understanding these issues more deeply. In addition, comparing interest maintenance in situations where a teacher's interest happens to match or not match a child's interest might also be informative.

Finally, although interest topics were gender-typed, boys and girls were equally likely to exhibit focused interests, their interests tended to last for about the same amount of time, and boys and girls exhibited similarly wide arrays of interest topics. Our results are consistent with those observed by Renninger and Wozniak (1985) in terms of the number of interests manifest by preschool children in the classroom and the gender differences noted converge with wellestablished patterns of observed childhood interests (Johnson et al., 1999). Thus, we are fairly confident that parents were not heavily influenced by demand characteristics in the reporting of their children's interests. Nevertheless, future research should additionally examine the degree of convergence among parent's, children's and teacher's reports of preferred interests and activities in order to gain additional perspectives on children's interests, especially during the transition to school. 


\section{Acknowledgements}

This research was supported by grants BCS-9907865 and BCS-0217466 from the National Science Foundation. We thank Fabiola Reis-Henrie and numerous research assistants at IUPUI and IU for their assistance on this project. We are grateful for the children and parents involved in the longitudinal study for their enthusiastic and tireless participation.

\section{References}

Ainley, M., Hidi, S., \& Berndorff, D. (2002). Interest, learning, and the psychological processes that mediate their relationships. Educational psychologist, 94, 545-561.

Alexander, J. M., Johnson, K. E., \& Schreiber, J. B. (2002). Knowledge is not everything: Analysis of children's performance on a haptic comparison task. Journal of Experimental Child Psychology, 82, 341-366.

Alexander, J.M., Johnson, K.E., Scott, B., \& Meyer, R.D. (2008). Stegosaurus and Spoonbills: Mechanisms for transfer across biological domains. In M.F. Shaughnessy, M.V. Veenman, \& C.K. Kennedy (Eds.), Metacognition: A Recent Review of Research, Theory, and Perspectives. Happauge, NY: Nova Publications.

Baron-Cohen, S. (2002). The extremely male brain theory of autism. Trends in Cognitive Sciences, 6, $248-254$.

Baron-Cohen, S. (2003). The essential difference: The truth about the male and female brain. New York: Basic Books.

Bergen, D. (1988). Stages of play development. In D. Bergen (Ed.), Play as a medium for learning and development: A handbook of theory and practice (pp. 49-67). Portsmouth, NH: Heinemann.

Chi, M. T. H., Hutchinson, J. E., \& Robin, A. F. (1989). How inferences about novel domain-related concepts can be constrained by structured knowledge. Merrill-Palmer Quarterly, 35, $27-62$.

Chi, M. T., \& Koeske, R. D. (1983). Network representation of a child's dinosaur knowledge. Developmental Psychology, 19, 29-39.

Chouinard, M. M. (2007). Children's questions: A mechanism for cognitive development. Monographs of the Society for Research in Child Development, 72, 1-108.

DeLoache, J. S., Simcock, G., \& Macari, S. (in press). Planes, trains, automobiles - and tea sets: Extremely intense interests in very young children. Developmental Psychology.

Dunlop, W. P., Cortina, J. M., Vaslow, J. B., \& Burke, M. J. (1996). Meta-analysis of experiments with matched groups or repeated measures designs. Psychological Methods, 1, 170-177.

Eccles, J., \& Midgley, C. (1990). Changes in academic motivation and self-perception during early adolescence. In R. Montemayor, G. R. Adams, \& T. P. Gullotta (Eds.), From childhood to adolescence: A transitional period? Advances in adolescent development: An annual book series (pp. 134-155). Thousand Oaks, CA: Sage.

Ericsson, K. A., \& Crutcher, R. J. (1990). The nature of exceptional performance. In P. B. Baltes, D. L. Featherman, \& al. et (Eds.), Life-span development and behavior, 10 (pp. 187-217). Hillsdale, NJ: Erlbaum.

Fernie, D. (1988). Becoming a student: Messages from first settings. Theory into Practice, 27, 3-10.

Fink, B. (1994). Interest and exploration: Exploratory action in the context of interest genesis. In H. Keller, K. Schneider, \& B. Henderson (Eds.), Curiosity and exploration (pp. 100-120). New York: Springer-Verlag.

Folling-Albers, M., \& Hartinger, A. (1998). Interest of girls and boys in elementary school. In L. Hoffmann, A. Krapp, K. A. Renninger, \& J. Baumert (Eds.), Interest and learning. Proceedings of the Seeon-conference on interest and gender (pp. 175-183). Kiel, Germany: IPN.

Ford, D. J., Brickhouse, N. W., Lottero-Perdue, P., \& Kilttleson, J. (2006). Elementary girls' science reading at home and school. Science Education, 90(2), 270-288.

Gardner, P. L. (1985). Students' attitudes to science and technology: An international overview. In M. Lehrke, L. Hoffman, \& P. L. Gardner (Eds.), Interests in science and technology education (pp. 15-34). 12th IPN-Symposium. IPNSchriftenreihe 102: Kiel: IPN.

Gobbo, C., \& Chi, M. (1986). How knowledge is structured and used by expert and novice children. Cognitive Development, 1, 221-237.

Hedeker, D., \& Gibbons, R. D. (2006). Longitudinal data analysis. New York: Wiley.

Hidi, S. (1990). Interest and its contribution as a mental resource for learning. Review of Educational Research, 60, $549-571$.

Hidi, S. (2000). An interest researcher's perspective: The effects of extrinsic and intrinsic factors on motivation. In C. Sansone \& H. M. Harackiewicz (Eds.), Intrinsic and extrinsic motivation: The search for optimal motivation and performance (pp. 309-339). Academic San Diego, CA: Academic Press. 
Hidi, S., \& Renninger, K. A. (2006). The four-phase model of interest development. Educational Psychologist, 41, $111-127$.

Hoffman, L. (2002). Promoting girls' interest and achievement in physics classes for beginners. Learning and Instruction, $12,447-465$.

Johnson, J. E., Christie, J. F., \& Yawkey, T. D. (1999). Play and early childhood development. New York: Longman.

Johnson, K. E. (2001). Determinants of typicality throughout the continuum of expertise. Memory \& Cognition, 29, $1036-1050$.

Johnson, K. E., Alexander, J. M., Spencer, S., Leibham, M. E., \& Neitzel, C. (2004). Factors associated with the early emergence of intense interests within conceptual domains. Cognitive Development, 19, 325-343.

Johnson, K. E., \& Eilers, A. T. (1998). Effects of knowledge and development on the extension and evolution of subordinate categories. Cognitive Development, 13, 515-545.

Johnson, K. E., \& Mervis, C. B. (1994). Microgenetic analysis of first steps in the acquisition of expertise on shorebirds. Developmental Psychology, 30, 418-435.

Johnson, K. E., \& Mervis, C. B. (1997). Effects of varying levels of expertise on the basic level of categorization. Journal of Experimental Psychology: General, 126, 248-277.

Johnson, K. E., \& Mervis, C. B. (1998). Impact of intuitive theories on feature recruitment throughout the continuum of expertise. Memory \& Cognition, 26, 382-401.

Johnson, K. E., Scott, P., \& Mervis, C. B. (2004). What are theories for? Concept use throughout the continuum of expertise. Journal of Experimental Child Psychology, 87, 171-200.

Klugman, E. (1990). Early childhood moves into the public schools: Mix or meld. In E. Klugman \& S. Smilansky (Eds.), Children's play and learning: Perspectives and policy implications (pp. 188-209). New York: Teachers College Press.

Krapp, A. (2002). Structural and dynamic aspects of interest development: Theoretical considerations from an ontogenetic perspective. Learning and Instruction, 12, 383-409.

Krapp, A., \& Fink, B. (1992). The development and function of interests during the critical transition from home to preschool. In K. A. Renninger, S. Hidi, \& A. Krapp (Eds.), The role of interest in learning and development (pp. 397-429). Hillsdale, NJ: Erlbaum.

Lavin, B. M., Gelman, R., \& Galotti, K. (2001). When children, not adults, are the experts. Explorations of the Pokémon phenomenon. In Poster presented at the meeting of the American Psychological Society.

Leibham, M. E., Alexander, J. M., Johnson, K. E., Neitzel, C., \& Reis-Henrie, F. (2005). Parenting behaviors associated with the maintenance of preschoolers' interests: A prospective longitudinal study. Journal of Applied Developmental Psychology, 26, 397-414.

Lytton, H., \& Romney, D. M. (1991). Parents' differential socialization of boys and girls: A meta-analysis. Psychological Bulletin, 109, 267-296.

Martin, C. L. (1999). A developmental perspective on gender effects and gender concepts. In W. B. Swann, J. H. Langlois, \& L. A. Gilbert (Eds.), Sexism and stereotypes in modern society: The gender science of Janet Taylor Spence (pp. 45-74). Washington, DC: American Psychological Association.

Mervis, C. B., Pani, J. R., \& Pani, A. M. (2003). Category formation and evolution: Transaction of child interest, background conceptual knowledge, linguistic knowledge, and adult input in the acquisition of lexical categories at the basic and subordinate levels. In D. H. Rakison \& L. M. Oakes (Eds.), Early category and concept development. Oxford: Oxford.

Moller, L. C., \& Serbin, L. A. (1996). Antecedents of toddler gender segregation: Cognitive consonance, gender-typed toy preferences and behavioral compatibility. Sex Roles, 35, 445-460.

Prenzel, M. (1992). The selective persistence of interest. In K. A. Renninger, S. Hidi, \& A. Krapp (Eds.), The role of interest in learning and development (pp. 71-98). Hillsdale, NJ: Erlbaum.

Renninger, K. A. (1989). Individual patterns in children's play interests. In L. T. Winegar (Ed.), Social interaction and the development of children's understanding (pp. 147-172). Norwood, NJ: Ablex.

Renninger, K. A. (1990). Children's play interest, representation, and activity. In R. Fivush \& J. A. Hudson (Eds.), Knowing and remembering in young children: Emory symposia in cognition (pp. 127-165). New York, NY: Cambridge University Press.

Renninger, K. A. (1992). Individual interest and development: Implications for theory and practice. In K. A. Renninger, S. Hidi, \& A. Krapp (Eds.), The role of interest in learning and development (pp. 361-395). Hillsdale, NJ: Erlbaum.

Renninger, K. A. (2000). Individual interest and its implications for understanding intrinsic motivation. In C. Sansone \& J. M. Harackiewicz (Eds.), Intrinsic and extrinsic motivation: The search for optimal motivation and performance (pp. 373-404). New York: Academic Press.

Renninger, K. A., \& Wozniak, R. H. (1985). Effect of interest on attentional shift, recognition, and recall in young children. Developmental Psychology, 21, 624-632.

Rosenthal, R. (1991). Meta-analytic procedures for social research. Newbury Park, CA: Sage. 
Saracho, O. (1995). Relationship between young children's cognitive style and their play. Early Childhood Development and Care, 113, 77-84.

Schiefele, U. (1998). Individual interest and learning - What we know and what we don't know. In L. Hoffman, A. Krapp, K. A. Renninger, \& J. Baumert (Eds.), Interest and learning: Proceedings of the Seeon Conference on Interest and Gender (pp. 91-104). Kiel, Germany: IPN.

Schiefele, U. (1999). Interest and learning from text. Scientific Studies of Reading, 3, 257-279.

Schiefele, U., \& Krapp, A. (1996). Topic interest and free recall of expository text. Learning \& Individual Differences, 8 , $141-160$.

Singer, J. D., \& Willett, J. B. (2003). Applied longitudinal data analysis: Modeling change and event occurrence. New York: Oxford University Press.

Smilansky, S. (1968). The effects of sociodramatic play on disadvantaged preschool children. New York: Wiley.

Watson, S. (2001). How Pokemon helps your child learn. Retrieved July 3, 2001 from www.parentcenter.com/ news/20010702?id=32521 